\title{
Research on the Monitoring of College English Learning Strategies under the Online Autonomous Learning Environment
}

\author{
Min Zhang and Yurong Hong \\ Northwest University, Xi'an 710127, China \\ zhangmin@nwu.edu.cn
}

\begin{abstract}
Keywords: College English Learning Strategies, Online Autonomous Learning Environment, Learning Monitoring
\end{abstract}

\begin{abstract}
This paper explores the relationship between independent learning monitoring and English academic achievement through experimental research. It provides theoretical and practical support for the construction of multi-inspection system of college English self-study based on online environment and the effective implementation of monitoring strategy. Based on the research results of pre-autonomous learning, it can be inferred that learning monitoring plays a relevant role in the improvement of self-learning ability and academic achievement. The education sector should carry out large-scale investigations and experiments, obtain detailed materials, summarize the experience, and extract the teaching guidance model that meets the characteristics of the development of independent English learning ability of Chinese students.
\end{abstract}

\section{College English Autonomous Learning Research}

Chinese scholars generally believe that self-directed learning means that students themselves dominate their own learning. Some researchers believe that autonomous learning is essentially a process in which learners independently determine individualized learning objectives, self-selected learning strategies, consciously monitor learning processes, and self-evaluate learning outcomes[1].

At the same time, the student is no longer mechanically copying the learning performance of the role model, but imitating the general learning mode and learning style of the model. Self-control stage refers to a stage when the learner is faced with the learning transfer task independently, if he can independently use the learning strategy, then his learning will enter a self-control stage. At this stage, the learning strategy has been internalized. The learner no longer needs to rely directly on the exemplary role of the role model, but to accept the representational characteristics of the role model's behavior and the impact of the self-reinforcing process on himself. Independent stage refers to the final stage of autonomous learning. Entering this stage of learning, people are often able to consciously use a variety of learning strategies, and can adjust their learning activities according to various situational characteristics, driven by goals and self-efficacy to achieve academic performances.

The essence of autonomous learning is self-regulation under the guidance of goals. Researchers advocate defining autonomous learning from both vertical and horizontal dimensions[2]. Defined from the perspective of horizontal learning aspects, the motivation of learners is self-motivated. The content is self-selective, the strategy is self-regulating, and time is self-managed. Students can also actively create a material environment and society that is conducive to learning. Self learning environment can make self-judgment and evaluation of learning outcomes. An autonomous learning model was designed based on the absorption of Bandura's personal, behavioral, environmental interaction determinism and self-regulation thinking (see Figure 1). 


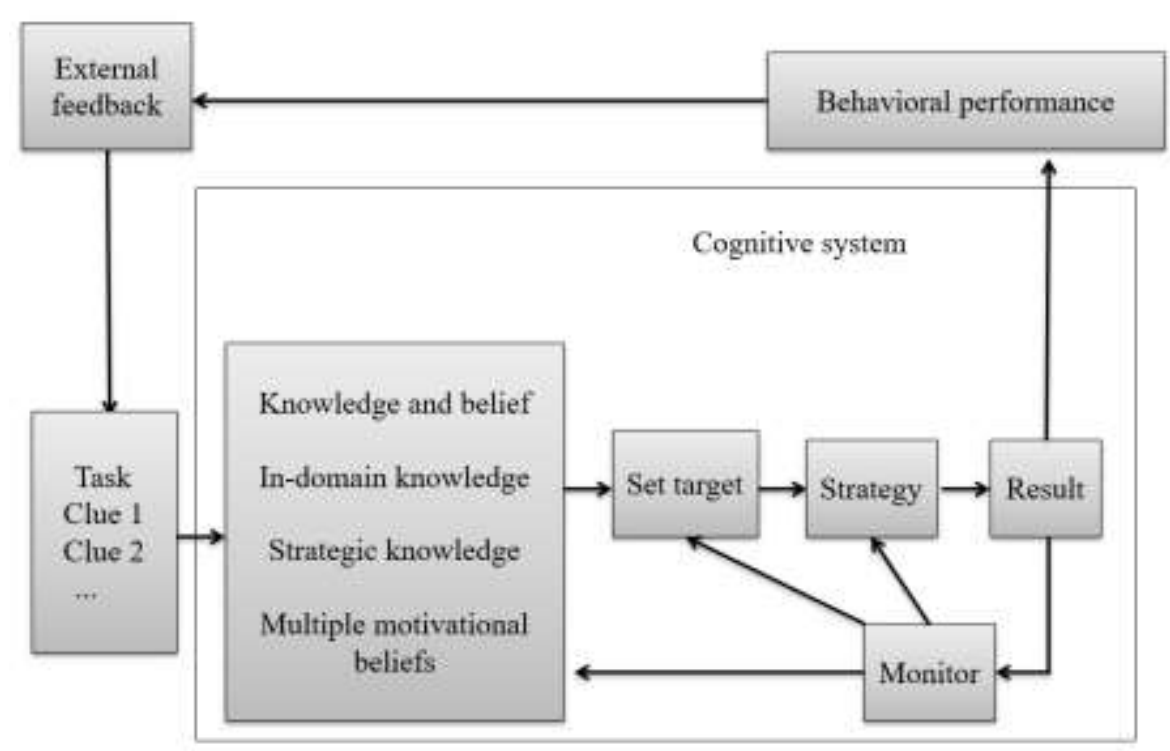

Figure 1 Autonomous learning model based on the absorption of Bandura

Regarding the study of the acquisition of autonomous learning ability, Zimmerman and Schunk, representatives of the social cognitive school, believe that this is a process of transforming external learning skills into learners' own abilities[3]. In general, this process requires a series of studies. The stage is embodied in the following four aspects: (1) Observation stage (mainly refers to the use of the model, the guidance, the encouragement of the learning strategy, and the integration of the main characteristics of the learning strategy into their own cognition); (2) Imitation stage (only when the learner's external learning performance is closer to the general form of the model's performance, this learning will be considered to reach the imitation level).

\section{The Status Quo of Autonomous Learning Monitoring in College English}

Due to the lack of understanding of teaching monitoring, college English teachers are not optimistic about the monitoring of independent learning. We conducted a questionnaire survey on the status quo of college English autonomous learning monitoring in Shaanxi universities. The questionnaire consists of two parts. The first part is the personal information of the respondents (including gender, age, academic degree and years of college English teaching). Although most teachers believe that college English self-learning based on online environment is not free-flowing, it is necessary for the academic sectors, teachers and network platform administrators to implement certain interventions. The actual monitoring effect of self-learning and the personal perception of teachers are quite different. At present, the self-learning monitoring of college English learning based on the online environment still has problems, such as lack of cognition, too little monitoring time, one-sided monitoring content, and single monitoring mode.

Some teachers still believe that self-study is a student's own business. Teachers should not interfere too much. Therefore, the second part is about the investigation of the status quo of English autonomous learning monitoring. This part consists of 22 questions, related to the cognitive, attitude, monitoring strategy, monitoring time, monitoring satisfaction, monitoring obstacles and other aspects of college English autonomous learning monitoring. Most of the respondents were between the ages of 31 40, and more than $53.5 \%$ of the teachers had more than 6 years of college English teaching experience (see Figure 2). 


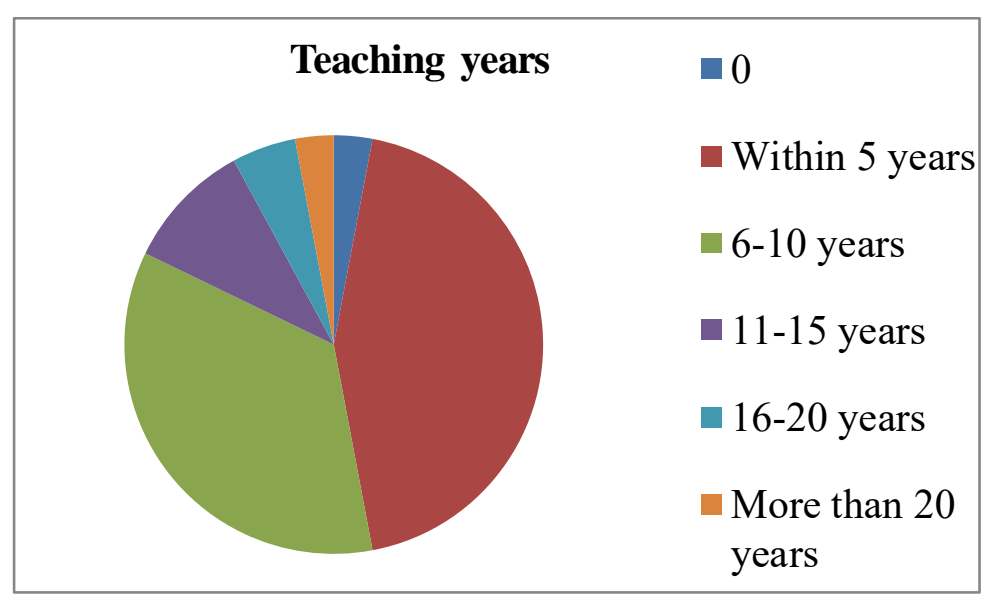

Figure 2 Respondents' years of college English teaching

It reveals that the current situation of independent monitoring of college English autonomous learning is not good, and the effect is not good. But when asked about the satisfaction of the surveyed teachers on the monitoring of their schools and individual teachers, most of the teachers feel good about themselves (see Table 1), which is quite different from the actual monitoring effect of independent learning. This shows that some college English teachers have a blindly optimistic and unrealistic attitude towards the current college English autonomous learning monitoring.

Table 1 Students' monitoring of autonomous learning

\begin{tabular}{|c|c|c|c|}
\hline & Cumulative Percent & Valid Percent & Frequency \\
\hline Valid & 2.4 & 2.4 & 5 \\
Totally dissatisfied & 8.1 & 5.7 & 0 \\
Usually not satisfied & 22.7 & 14.7 & 31 \\
Not stated & 60.7 & 37.9 & 80 \\
Satisfied & 96.2 & 35.5 & 75 \\
Very satisfied & 100 & 3.8 & 8 \\
Total & 100.0 & 100.0 & 211 \\
\hline
\end{tabular}

A student with a strong self-learning ability must be very clear about his or her learning goals and be able to set up a learning plan scientifically. Through the use of relevant learning strategies, learners can actively adjust, monitor and actively cooperate with peers in a timely manner, and evaluate and check the learning results in multiple ways. However, because absolute learner autonomy is impossible, the learning autonomy of college students will be affected by many factors, such as learner attitude, belief, learning motivation, cultural factors, teacher intervention and environmental factors. Therefore, it is necessary to properly intervene in the English autonomous learning of college students. In particular, the training strategy and meta-cognitive monitoring strategy training stimulate students' self-regulation motivation, enhance self-regulation ability, and actively play the role of teacher guidance and support, so as to fully realize learner autonomy.

\section{Construction of Multi-Disciplinary Monitoring System for College English Autonomous Learning}

Learners' self-monitoring characteristics are guided and helped by teachers' guidance in four aspects: first, the planning and arrangement of their own learning activities; second, the supervision, evaluation and feedback of their actual learning activities; third, the correcting and control of their own learning activities; fourth, self-evaluation and mutual evaluation are carried out while fully completing the whole process of self-learning supplemented by network courseware, network teaching platform resource, and library and test platform[5].

Self-directed learning and monitoring is a systematic project that requires full participation. We should establish a multi-disciplinary monitoring system involving classroom teachers, grade counselors, independent learning center administrators, students and student peers. We should fully mobilize everyone's enthusiasm to form synergy, and strengthen the management of students' 
independent learning. It not only manages the class's in-class and out-of-class learning content, learning process, but also manages the arrangement and use of equipment, understands students and helps students improve their language skills and manage student information. By establishing a learning log that automatically records the student's learning time and learning content, teachers can review the student's logging time, number of loggings, learning items, learning time, number of discussions, and statistical analysis of test results. Teachers can also provide reasonable guidance.

\section{Conclusion}

College English autonomous learning monitoring refers to the purpose of improving college English learning, achieving college English teaching goals, and ensuring successful learning. In the whole process of foreign language learning activities, the ongoing learning activities are regarded as the object of consciousness. And they are continuously conscious of planning, monitoring, inspection, evaluation, feedback, control and regulation. The independent monitoring of college English learning is not carried out in isolation. It requires the participation of students, teachers, educational administration, teaching supervision and network technology monitoring. Therefore, it is necessary to establish a multi-dimensional monitoring system.

\section{References}

[1] Asheralieva, A. and Y. Miyanaga, An Autonomous Learning-Based Algorithm for Joint Channel and Power Level Selection by D2D Pairs in Heterogeneous Cellular Networks. IEEE Transactions on Communications, 2016. PP(99): p. 1-1.

[2] Misra, S., et al., Learning Automata-Based Fault-Tolerant System for Dynamic Autonomous Unmanned Vehicular Networks. IEEE Systems Journal, 2017. PP(99): p. 1-10.

[3] Silva, E.P.E., et al., Autonomous Learning Architecture for Environmental Mapping. Journal of Intelligent \& Robotic Systems, 2004. 39(3): p. 243-263.

[4] Sikora, R.T. and V. Sachdev, Learning bidding strategies with autonomous agents in environments with unstable equilibrium $\hat{z}$. Decision Support Systems, 2009. 46(1): p. 101-114.

[5] Zoha, A., et al., A learning - based approach for autonomous outage detection and coverage optimization. Transactions on Emerging Telecommunications Technologies, 2016. 27(3): p. 439-450. 